\title{
Association between Bone Mineral Density and Serum Iron Indices in Premenopausal Women in South Korea
}

\author{
Sung-Min Kim ${ }^{1}$, A-Sol Kim²,3,* Hae-Jin Ko ${ }^{1,2}$, Hana Moon ${ }^{3}$, Hye-In Choi', Jieun Song' \\ 'Department of Family Medicine, Kyungpook National University Hospital, Daegu, Korea \\ ${ }^{2}$ Department of Family Medicine, School of Medicine, Kyungpook National University, Daegu, Korea \\ ${ }^{3}$ Department of Family Medicine, Kyungpook National University Chilgok Hospital, Daegu, Korea
}

Background: Osteoporosis is characterized by a decrease in bone mineral density (BMD) and increased risk of fragility fractures. Serum iron level may interact with bone health status. This study investigated the correlations of BMD with serum iron level, hemoglobin level, and total iron-binding capacity (TIBC).

Methods: We performed a retrospective analysis of data from the medical records of premenopausal women in South Korea. The women's BMDs and the Z scores of the BMDs were verified using dual-energy X-ray absorption. The participants were stratified into quartiles for analyses of the associations of BMD with serum iron level, TIBC, and hemoglobin level.

Results: A simple linear regression analysis revealed associations of changes in BMD with iron level $(\beta=-0.001$, standard error $[\mathrm{SE}]=0.001, \mathrm{P}<0.001)$, hemoglobin level $(\beta=0.015$, SE $=0.003, \mathrm{P}<0.001)$, and TIBC $(\beta=0.001, \mathrm{SE}=0.001$, $\mathrm{P}<0.001)$. This pattern was also observed in a multiple linear regression analysis. A multivariate logistic regression analysis of iron level and TIBC for low BMD revealed odds ratios of $1.005(\mathrm{P}<0.001)$ and $0.995(\mathrm{P}<0.001)$, respectively. Conclusion: This study demonstrated clear relationships of changes in BMD with serum iron level and TIBC, and thus confirms the usefulness of these markers in the clinical evaluation of iron storage and BMD in younger women.

Keywords: Bone and Bones; Bone Disease; Trace Elements; Premenopause; Women; Bone Density

Received: August 6, 2018, Revised: January 3, 2019, Accepted: January 9, 2019

*Corresponding Author: A-Sol Kim https://orcid.org/0000-0003-2497-9500

Tel: +82-53-200-3440, Fax: +82-53-200-3459, E-mail: deepai@knu.ac.kr 


\section{INTRODUCTION}

Osteoporosis is a musculoskeletal disease characterized by decreased bone mineral density (BMD) and increased risk of fragility fractures. ${ }^{1)}$ According to the World Health Organization, osteoporosis is defined as a BMD of $\geq 2.5$ standard deviations below the mean peak BMD for healthy adults, as measured with dual energy X-ray absorption (DXA) ${ }^{2)}$ For the treatment of osteoporosis, the annual associated medical expenditures are estimated to exceed \$175 million in South Korea. ${ }^{3)}$

Osteoporosis and osteopenia have a multifactorial etiology in which many factors, including genetic differences, endocrine factors, and lifestyle behaviors (e.g., physical activity and diet), have been suggested as important contributors. Mineral deficiencies due to reduced dietary intakes and absorption of particular nutrients have been identified as important in both the etiology and prevention of osteopenia and osteoporosis. ${ }^{4,5)}$ For example, trace minerals, defined as micronutrients required by the body in minute quantities, ${ }^{6)}$ may be important components of bone quality maintenance via their functions in the context of metalloenzymes that promote the synthesis of collagen and other proteins that form the bone structure. ${ }^{7)}$

Iron is an essential trace mineral with several roles in various enzymatic systems in the body, including collagen synthesis. ${ }^{8,9)}$ As type I collagen accounts for approximately $90 \%$ of total bone protein, iron participates in bone metabolism via this mechanism and through vitamin D activation and deactivation. ${ }^{10)}$ However, excessive iron levels have toxic effects such as cellular dysfunction, which are mainly due to the powerful ability of iron to catalyze the generation of highly toxic free radicals that damage all molecular classes found in vivo. ${ }^{11)}$

Many studies have been conducted to determine the relationship between serum iron level and BMD by using ferritin or hemoglobin level; ${ }^{12)}$ however, ferritin levels may be artificially elevated in response to systemic inflammation, ${ }^{13)}$ and hemoglobin level remains normal during stage 1 iron deficiency. ${ }^{14)}$ As mentioned earlier, excess iron in serum may lead to bone mass loss; ${ }^{15)}$ therefore, we used not only total iron-binding capacity (TIBC) and hemoglobin level but also serum iron level to study the relationship between serum iron level and BMD.

Previous studies reported a negative correlation or no significant association between serum iron level and BMD. ${ }^{15,16)}$ By contrast, another study that involved a general population without hematologic disorders identified a potential positive correlation between iron stores and BMD. ${ }^{12)}$ Although the relationship between serum iron level and BMD is interesting, it is not yet fully elucidated. Therefore, in this study, we investigated the correlations of changes in BMD with serum iron and hemoglobin levels and TIBC in a cohort of healthy premenopausal women in South Korea.

\section{METHODS}

\section{Participants}

The population of this retrospective study was comprised of women aged 20-49 years who had undergone comprehensive routine health examinations at a general hospital health examination center in a single region between January 2014 and December 2016, and measurements of BMD and serum iron index levels. Menstrual status was assessed to confirm premenopausal states, and 21 women were excluded. We also excluded participants who did not complete the self-reported medical history questionnaire and those who had undergone gastrectomy or had been diagnosed with and treated for anemia, osteoporosis, thyroid disease, or parathyroid disease. Those who took medications that may have affected their BMD measurements (e.g., calcium or vitamin D supplements; steroids; exogenous female hormones, including contraceptives; thyroid hormones; and proton pump inhibitor) were also excluded. Finally, 1,020 healthy premenopausal women were enrolled in the study (Figure 1). This study protocol was approved by the institutional review board of Kyungpook National University Chilgok Hospital (2018-03-014). The requirement for informed patient consent was waived because of the retrospective study design of the study.

\section{Women aged $20-49$ years \\ 1,145 were assessed for eligibility \\ (January 2014-December 2016)}

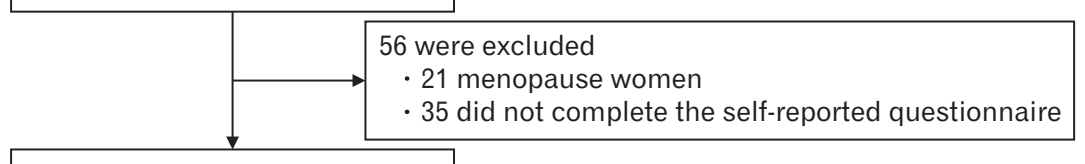

1,089 were screened

\begin{tabular}{|l|l|}
\hline & $\begin{array}{l}69 \text { were excluded who meet exclusion criteria } \\
\cdot 3 \text { undergone gastrectomy } \\
\cdot 12 \text { diagnosed with and treated for anemia } \\
\cdot 8 \text { diagnosed with and treated for osteoporosis } \\
\cdot 11 \text { diagnosed with and treated for thyroid or parathyroid disease } \\
\cdot 35 \text { took medication which affect to the bone mineral density }\end{array}$ \\
\cline { 2 - 3 } &
\end{tabular}

Figure 1. Flowchart of the enrollment of premenopausal women with routine health examinations. 


\section{General Characteristics and Anthropometrics}

Information about demographic factors, alcohol intake, smoking and exercise habits, and medical history was collected via self-reported questionnaires. Alcohol intake was assessed on the basis of the reference criteria of the National Institute on Alcohol Abuse and Alcoholism, ${ }^{17)}$ and the participants were classified as never, moderate, or heavy drinkers if they reported consuming $\leq 1,1-7$, or $>7$ standard drinks per week, respectively. Women with a smoking behavior were stratified as either a never smoker or an ex/current smoker if they reported that they had not or had ever tried smoking, respectively. Physical exercise practices were classified as none, inactive, and active if the participants reported that they did not exercise, exercised for $\leq 150$ minutes per week, or exercised for $>150$ minutes per week, respectively.

Anthropomorphic measurements were obtained by trained staff members. Height was measured within $0.1 \mathrm{~cm}$ and body weight was measured with a metric weight scale to the nearest $0.01 \mathrm{~kg}$, with the participants wearing light clothing without shoes. Body mass index (BMI) was calculated as weight divided by height squared $\left(\mathrm{kg} / \mathrm{m}^{2}\right)$. BMD was measured on DXA scans (Discovery-W; Hologic, Bedford, MA, USA) of the lumbar spine (L1-L4 vertebrae). All the measurements were performed by experienced operators who followed stan- dardized procedures.

\section{Biochemical Variables and Serum Iron Indexes}

Blood samples were collected after a minimum fasting period of 8 hours. White blood cells; platelet count; levels of hematocrit, aspartate transaminase, alanine transaminase, serum creatinine, alkaline phosphatase, and serum iron; TIBC; and hemoglobin level were measured using CellDyn 4000 (Abbott Diagnostics, Abbott Park, IL, USA). Serum iron level and TIBC were measured using the FerroZine method. ${ }^{18)}$ All laboratory examinations were conducted at the same center.

\section{Statistical Analyses}

For the analysis of the women's baseline characteristics according to BMD status, one-way analysis of variance (ANOVA) was used for continuous variables, and chi-square test and Fisher exact test were used for categorical variables. One-way ANOVA was used to observe differences in mean BMD values according to iron level, TIBC, and hemoglobin quartile groups. Ranges for the quartile groups of iron levels were quartile $1(<104.7 \mu \mathrm{g} / \mathrm{dL})$, quartile $2(104.7-147.2 \mu \mathrm{g} / \mathrm{dL})$, quartile $3(147.2-294.0 \mu \mathrm{g} / \mathrm{dL})$, and quartile $4(>294.0 \mu \mathrm{g} / \mathrm{dL})$. The ranges for the quartile groups of TIBC values were quartile $1(<171.0 \mu \mathrm{g} / \mathrm{dL})$,

Table 1. Baseline characteristics of the study subjects according to bone mineral density

\begin{tabular}{|c|c|c|c|c|c|c|}
\hline Characteristic & Q1 $(<1.001)$ & Q2 (1.001-1.110) & Q3 (1.110-1.212) & Q4 (>1.212) & P-value* & P for trend \\
\hline No. of subjects & 255 & 254 & 257 & 253 & & \\
\hline Age (y) & $41.47 \pm 6.53$ & $41.26 \pm 6.28$ & $40.91 \pm 5.79$ & $42.27 \pm 5.79$ & 0.064 & 0.220 \\
\hline Height (cm) & $163.07 \pm 7.38$ & $167.61 \pm 8.43$ & $168.35 \pm 8.32$ & $168.57 \pm 7.97$ & $<0.001$ & $<0.001$ \\
\hline Weight (kg) & $60.11 \pm 11.14$ & $66.42 \pm 12.69$ & $67.64 \pm 12.90$ & $67.49 \pm 12.42$ & $<0.001$ & $<0.001$ \\
\hline Body mass index $\left(\mathrm{kg} / \mathrm{m}^{2}\right)$ & $22.50 \pm 3.14$ & $23.50 \pm 3.23$ & $23.72 \pm 3.31$ & $23.62 \pm 3.22$ & $<0.001$ & $<0.001$ \\
\hline White blood cell count $\left(10^{3} / \mu \mathrm{L}\right)$ & $5.82 \pm 1.77$ & $5.79 \pm 1.70$ & $5.78 \pm 1.65$ & $5.78 \pm 1.61$ & 0.995 & 0.812 \\
\hline Platelet count $\left(10^{3} / \mu \mathrm{L}\right)$ & $267.06 \pm 59.70$ & $250.50 \pm 61.60$ & $247.54 \pm 59.78$ & $253.89 \pm 59.53$ & 0.001 & 0.012 \\
\hline Hemoglobin $(\mathrm{g} / \mathrm{dL})$ & $13.96 \pm 1.53$ & $14.53 \pm 1.63$ & $14.52 \pm 1.79$ & $14.78 \pm 1.74$ & $<0.001$ & 0.549 \\
\hline Hematocrit (\%) & $41.74 \pm 4.08$ & $43.12 \pm 4.19$ & $43.29 \pm 4.73$ & $43.84 \pm 4.56$ & $<0.001$ & 0.393 \\
\hline Serum iron $(\mu \mathrm{g} / \mathrm{dL})$ & $265.10 \pm 54.04$ & $179.73 \pm 78.64$ & $166.93 \pm 62.60$ & $135.78 \pm 68.27$ & $<0.001$ & $<0.001$ \\
\hline Total iron-binding capacity ( $\mu \mathrm{g} / \mathrm{dL})$ & $189.35 \pm 45.00$ & $266.21 \pm 57.12$ & $281.65 \pm 61.18$ & $308.85 \pm 72.36$ & $<0.001$ & $<0.001$ \\
\hline Serum aspartate transaminase (U/L) & $23.29 \pm 8.18$ & $23.271 \pm 11.93$ & $23.34 \pm 10.28$ & $22.57 \pm 11.33$ & 0.820 & 0.478 \\
\hline Serum alanine transaminase (U/L) & $20.09 \pm 15.26$ & $22.80 \pm 18.95$ & $23.53 \pm 18.03$ & $22.50 \pm 17.61$ & 0.134 & 0.105 \\
\hline Serum creatinine (mg/dL) & $0.76 \pm 0.16$ & $0.82 \pm 0.18$ & $0.84 \pm 0.17$ & $0.84 \pm 0.17$ & $<0.001$ & $<0.001$ \\
\hline Serum alkaline phosphatase (U/L) & $67.35 \pm 22.45$ & $72.00 \pm 25.88$ & $69.38 \pm 26.47$ & $72.27 \pm 26.23$ & 0.091 & 0.088 \\
\hline $\mathrm{BMD}\left(\mathrm{g} / \mathrm{cm}^{2}\right)$ & $0.917 \pm 0.074$ & $1.057 \pm 0.031$ & $1.161 \pm 0.030$ & $1.309 \pm 0.076$ & $<0.001$ & $<0.001$ \\
\hline Z score of BMD & $-1.59 \pm 0.62$ & $-0.73 \pm 0.52$ & $0.09 \pm 0.46$ & $1.18 \pm 0.68$ & $<0.001$ & $<0.001$ \\
\hline Alcohol intake & & & & & 0.001 & \\
\hline Never & $206(80.5)$ & $178(70.1)$ & $169(65.8)$ & $170(67.2)$ & & \\
\hline Moderate & $47(18.4)$ & $69(27.2)$ & $87(33.9)$ & $79(31.2)$ & & \\
\hline Heavy & $3(1.2)$ & $7(2.8)$ & $1(0.4)$ & $4(1.6)$ & & \\
\hline Smoking status & & & & & 0.361 & \\
\hline Never & $251(98.0)$ & 251 (98.8) & $256(99.6)$ & 251 (99.2) & & \\
\hline Ex/current smoker & $5(2.0)$ & $3(1.2)$ & $1(0.4)$ & $2(0.8)$ & & \\
\hline Exercise & & & & & $<0.001$ & \\
\hline None & $159(62.1)$ & 77 (30.3) & $90(35.0)$ & 79 (31.2) & & \\
\hline Inactive & 70 (27.3) & $145(57.1)$ & $132(51.4)$ & $142(56.1)$ & & \\
\hline Active & 27 (10.5) & $32(12.6)$ & $35(13.6)$ & $32(12.6)$ & & \\
\hline
\end{tabular}

Values are presented as number, mean \pm standard deviation, or number (\%).

$\mathrm{BMD}$, bone mineral density.

*By analysis of variance for quantitative variables and Freeman-Halton extension of the Fisher exact test for qualitative variables. 
quartile 2 (171.0-295.1 $\mu \mathrm{g} / \mathrm{dL})$, quartile 3 (295.1-330.3 $\mu \mathrm{g} / \mathrm{dL})$, and quartile 4 ( $>330.3 \mu \mathrm{g} / \mathrm{dL})$. The ranges for the quartile groups of hemoglobin levels were quartile $1(<13.3 \mathrm{~g} / \mathrm{dL})$, quartile $2(13.3-14.4 \mathrm{~g} / \mathrm{dL})$, quartile 3 (14.4-15.7 g/dL), and quartile 4 (>15.7 g/dL). Simple and multiple linear regression analyses were used to determine the independent effects of serum iron level, TIBC, and hemoglobin level on BMD in our population of premenopausal South Korean women, and partial correlation analyses were conducted to control for the effects of BMI, age, exercise, and alcohol intake. Univariate and multivariate logistic regression analyses were performed to evaluate the associations of BMD with iron level, TIBC, and hemoglobin level. Young women with BMD Z scores of $<-2$ were categorized as having a BMD "below the expected range for age," and those with $\mathrm{Z}$ scores of >-2 were categorized as having a BMD "within the expected range for age." ${ }^{19)}$ Therefore, we considered BMD Z scores below -2 as a low BMD. A statistical analysis was performed using the IBM SPSS ver. 23.0 software (IBM Corp., Armonk, NY, USA), and P-values of $<0.05$ were considered significant.

\section{RESULTS}

\section{Characteristics}

Table 1 shows the baseline characteristics of the study participants according to quartile 1-4 groups of BMD of the lumbar vertebra. Ranges for the quartile groups of BMD were quartile $1\left(<1.001 \mathrm{~g} / \mathrm{cm}^{2}\right)$, quartile 2 (1.001-1.110 g/ $\left.\mathrm{cm}^{2}\right)$, quartile $3\left(1.110-1.212 \mathrm{~g} / \mathrm{cm}^{2}\right)$, and quartile 4 $\left(>1.212 \mathrm{~g} / \mathrm{cm}^{2}\right)$.

No significant difference was found in the mean age of each quartile group. However, significant differences in height, weight, and BMI were found between the groups $(\mathrm{P}<0.001$ for all). The subjects with high values for height, body weight, and BMI had high BMDs. The groups with higher BMDs showed greater values for height, body weight, and BMI (P for trend $<0.001$ for all). The serum iron levels, TIBC, and hemoglobin levels in each group were statistically significant $(\mathrm{P}<0.001$ for all). The mean serum iron levels in the BMD quartile 1, 2, 3, and 4 groups were $265.10 \mu \mathrm{g} / \mathrm{dL}, 179.73 \mu \mathrm{g} / \mathrm{dL}, 166.393 \mu \mathrm{g} / \mathrm{dL}$, and $135.78 \mu \mathrm{g} / \mathrm{dL}$, respectively. The mean TIBC values of the groups were $189.35 \mu \mathrm{g} / \mathrm{dL}, 266.21$ $\mu \mathrm{g} / \mathrm{dL}, 281.65 \mu \mathrm{g} / \mathrm{dL}$, and $308.85 \mu \mathrm{g} / \mathrm{dL}$, respectively, and the mean hemoglobin levels were $13.96 \mathrm{~g} / \mathrm{dL}, 14.53 \mathrm{~g} / \mathrm{dL}, 14.52 \mathrm{~g} / \mathrm{dL}$, and $14.78 \mathrm{~g} /$ $\mathrm{dL}$, respectively. The mean serum iron level was lower and the mean TIBC was higher in the higher BMD group ( $\mathrm{P}$ for trend $<0.001$ for all).

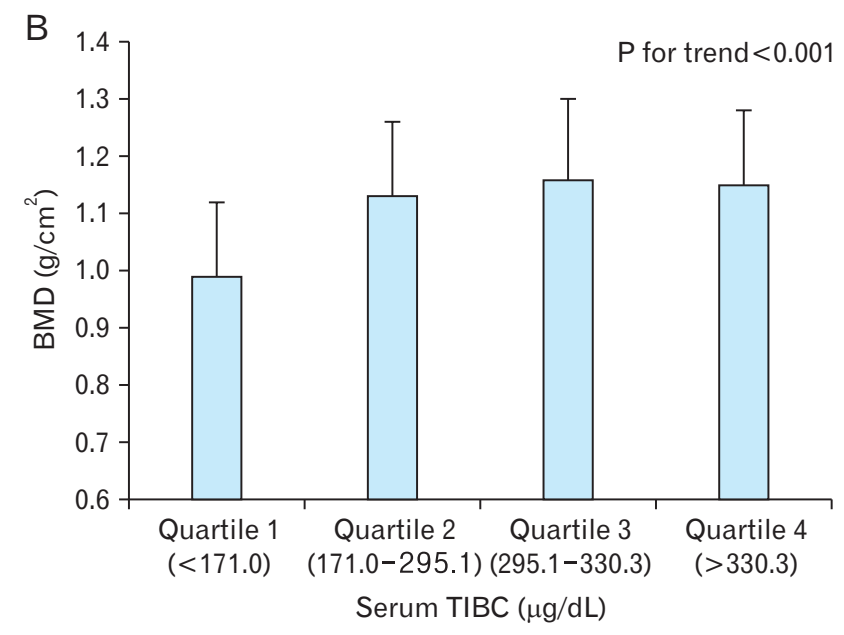

Figure 2. Mean BMD in four quartile groups according to serum iron (A), TIBC (B) and hemoglobin $(C)$ levels. In Figure 2, premenopausal women showed significantly decreased tendency in BMD as serum iron increased in quartiles ( $P$ for trend $<0.001)$. But those showed significantly increased tendency in BMD as TIBC and hemoglobin increased in quartiles ( $P$ for trend $<0.001,<0.001$, respectively). TIBC, total iron binding capacity; BMD, bone mineral density. 
The levels of alcohol consumption and physical activity were significantly different among the groups $(\mathrm{P}=0.001$ and $\mathrm{P}<0.001$, respectively), but no significant difference in smoking status was found $(\mathrm{P}=0.361)$.

\section{Associations of Bone Mineral Density with Iron, Total Iron-Binding Capacity, and Hemoglobin Quartiles}

The mean BMDs of the women in iron quartiles 1,2, 3, and 4 were 1.14 $\mathrm{g} / \mathrm{cm}^{2}, 1.17 \mathrm{~g} / \mathrm{cm}^{2}, 1.12 \mathrm{~g} / \mathrm{cm}^{2}$, and $0.99 \mathrm{~g} / \mathrm{cm}^{2}$, respectively. The mean BMDs in TIBC quartiles $1,2,3$, and 4 were $0.99 \mathrm{~g} / \mathrm{cm}^{2}, 1.13 \mathrm{~g} / \mathrm{cm}^{2}, 1.16$ $\mathrm{g} / \mathrm{cm}^{2}$, and $1.15 \mathrm{~g} / \mathrm{cm}^{2}$, respectively. The mean BMD values in hemoglobin quartiles $1,2,3$, and 4 were $1.09 \mathrm{~g} / \mathrm{cm}^{2}, 1.08 \mathrm{~g} / \mathrm{cm}^{2}, 1.12 \mathrm{~g} / \mathrm{cm}^{2}$, and $1.16 \mathrm{~g} / \mathrm{cm}^{2}$, respectively. These trends were significant in each quartile analysis ( $\mathrm{P}$ for trend $<0.001$ for all) (Figure 2).

Table 2. Association between bone mineral density and serum iron indexes

\begin{tabular}{lrr}
\hline \multicolumn{1}{c}{ Variable } & \multicolumn{1}{c}{$\mathrm{r}^{*}$} & P-value \\
\hline Serum iron $(\mu \mathrm{g} / \mathrm{dL})$ & -0.410 & $<0.001$ \\
Total iron-binding capacity $(\mu \mathrm{g} / \mathrm{dL})$ & 0.413 & $<0.001$ \\
Hemoglobin $(\mathrm{g} / \mathrm{dL})$ & 0.151 & $<0.001$
\end{tabular}

*Partial correlation coefficient adjusted for body mass index, age, exercise, and alcohol intake.


\section{Analysis of the Correlations of Bone Mineral Density with Serum Iron Level, Total Iron-Binding Capacity, and Hemoglobin Level}

We conducted a partial correlation analysis in which the coefficients of correlation were adjusted to control for the effects of BMI, age, and exercise and expressed as partial correlation coefficients. This analysis revealed that serum iron level (partial correlation coefficient, -0.410 ; $\mathrm{P}<0.001)$ correlated negatively with $\mathrm{BMD}$, whereas TIBC and hemoglobin level correlated positively with $\mathrm{BMD}(0.413, \mathrm{P}<0.001$ and 0.151 , $\mathrm{P}<0.001$, respectively) (Table 2 ).

We also conducted a simple linear regression analysis of the BMD correlations with iron level, TIBC, and hemoglobin level. The regression coefficients (standard errors) for the correlations of BMD with iron level, TIBC, and hemoglobin level were -0.001 (0.001), 0.001 (0.001), and 0.015 (0.003), respectively, and all were statistically significant $(\mathrm{P}<0.001$ for all). After adjusting for cofounding factors (BMI, age, exercise, and hemoglobin), the regression coefficients of BMD with iron level, TIBC, and hemoglobin level were -0.001 (0.001) and 0.001 (0.001), and 0.008 (0.003), respectively. All correlations were significant $(\mathrm{P}<0.001, \mathrm{P}<0.001$, and $\mathrm{P}=0.003$, respectively) (Figure 3).

\section{Effect of Serum Iron Indexes on the Risk of Low Bone Mineral Density}

We also conducted a logistic regression analysis and found that higher

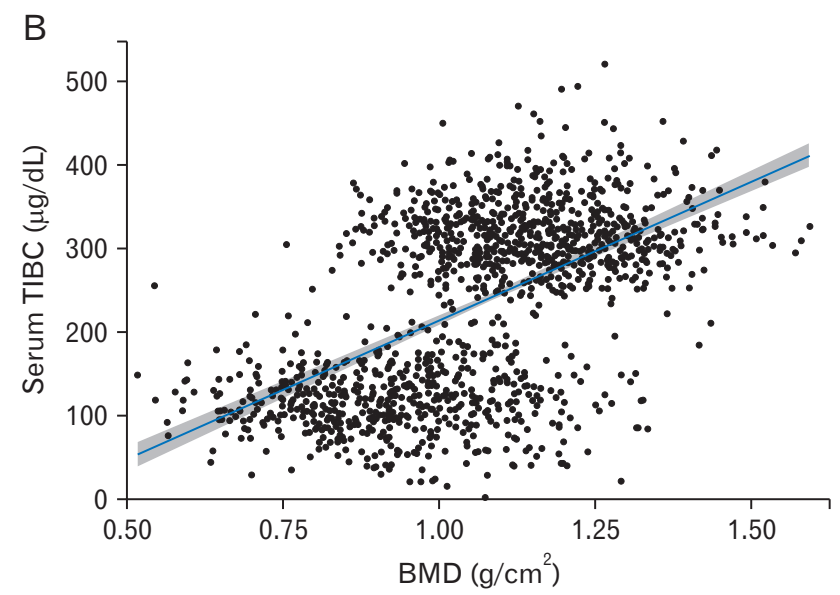

Figure 3. Scatter plot for iron level (A), TIBC (B), hemoglobin level (C) in association with $B M D$. The regression coefficients of iron level $(\beta=-0.001, S E=0.001, P<0.001)$, TIBC $(\beta=0.001, S E=0.001, P<0.001)$, and hemoglobin level $(\beta=0.015, S E=0.003$, $\mathrm{P}<0.001)$ significantly correlated with the changes in $\mathrm{BMD}$. TIBC, total iron binding capacity; BMD, bone mineral density; SE, standard error. 
Table 3. Effects of the serum iron indexes on the risk of low bone mineral density

\begin{tabular}{lccccc}
\hline \multirow{2}{*}{ Variable } & \multicolumn{2}{c}{ Univariate } & & Multivariate $^{*}$ \\
\cline { 2 - 6 } & OR $(95 \% \mathrm{Cl})$ & P-value & OR $(95 \%$ Cl) & P-value \\
\hline Serum iron $(\mu \mathrm{g} / \mathrm{dL})$ & $1.004(1.002-1.006)$ & $<0.001$ & & $1.005(1.002-1.007)$ & $<0.001$ \\
Total iron-binding capacity $(\mu \mathrm{g} / \mathrm{dL})$ & $0.995(0.993-0.998)$ & $<0.001$ & & $0.995(0.992-0.997)$ & $<0.001$ \\
Hemoglobin $(\mathrm{g} / \mathrm{dL})$ & $0.857(0.745-0.986)$ & 0.031 & & $0.871(0.752-1.009)$ & 0.065 \\
\hline
\end{tabular}

The subjects were classified by bone mineral density $Z$ scores.

$\mathrm{OR}$, odds ratio; $\mathrm{Cl}$, confidence interval.

*Adjusted for alcohol intake, smoking, exercise, age, and body mass index.

iron level was associated with a significantly greater risk of decreased BMD, both before and after adjusting for cofounding factors (alcohol, smoking, exercise, age, and BMI; odds ratio (OR), 1.004 and 1.005, respectively). Conversely, higher TIBC was associated with a significantly reduced risk of decreased BMD both before and after adjustment (OR, 0.995 and 0.995, respectively). However, higher hemoglobin level was associated with a significantly reduced risk of decreased BMD before adjustment (OR, 0.857); however, the association was not significant after adjustment (OR, 0.871) (Table 3).

\section{DISCUSSION}

In this study, we investigated the association between BMD of the lumbar vertebra and serum iron level, TIBC, and hemoglobin level in a population of premenopausal South Korean women. We observed that BMD exhibited a significant negative association with serum iron level and a significant positive association with TIBC and hemoglobin level. However, the effect of hemoglobin level on the risk of low BMD remains unclear. These results are consistent with findings from previous studies. In an animal study, micro-computed tomography analysis of trabecular bone (distal femur) revealed decreases in bone volume fraction, number of trabeculae, and trabecular thickness, and an increase in trabecular spacing in iron-overloaded mice, as compared with placebo-treated mice. A further analysis of cortical bone (mid-diaphysis femur) in the study revealed relatively thinner cortices and reduced cortical areas in the iron-overloaded animals. ${ }^{20)}$ Other studies reported higher iron concentrations in osteopenic postmenopausal women. ${ }^{21)}$

Although the mechanisms underlying the development of iron overload-related osteoporosis are not fully understood, ${ }^{13)}$ some explanations have been proposed for the relationship between BMD and serum iron level. In an iron-overloaded status, excess iron (i.e., unbound to transferrin) may cause tissue damage via cellular injury mediated through the Fenton and Haber-Weiss reactions, ${ }^{22)}$ which generate oxyradicals. ${ }^{14)}$ As mentioned earlier, iron was found to play roles in the synthesis of collagen and the conversion of 25-hydroxy vitamin D into an active form. ${ }^{11)}$ Furthermore, the inhibitory effects of iron on osteoblastogenesis in various osteoblast lineages might also explain the negative relationship between iron level and BMD change. ${ }^{23)}$

TIBC is an indirect measure of serum transferrin level. ${ }^{24)} \mathrm{A}$ previous study in women identified a positive correlation between serum TIBC and annual changes in the BMD of the total femur. ${ }^{23)}$ Similarly, we identified a significant association between TIBC and increased BMD of the lumbar spine. Our selection criteria excluded participants who had been diagnosed with anemia. However, hemoglobin and serum iron levels remain normal during stage 1 iron deficiency, and the compensatory increase in iron absorption causes an increase in iron-binding capacity (i.e., transferrin level). ${ }^{25)}$ Accordingly, some of our participants may have had stage 1 iron deficiency anemia, which could have affected our results.

We did not observe a clear association between hemoglobin level and BMD in our study. By contrast, Cesari et al. ${ }^{26)}$ reported lower BMD values, particularly in the cortical bone, in older community-dwelling persons with lower hemoglobin levels or anemia. Another study observed a significant correlation between low hemoglobin level and low bone mass in healthy young people. ${ }^{27)}$ The discrepancy between our results and those of previous studies might be attributable to the exclusion of women diagnosed as having and treated for anemia from our study population. Each month, healthy women lose approximately 70 $\mathrm{mL}$ of blood via menstruation; this adds up to an approximate rate of $850 \mathrm{~mL}$ per year and $30 \mathrm{~L}$ over a 35 -year reproductive period. This blood loss places pressure on the hematopoietic system by augmenting the production of hematopoietic growth factors to subsequently enhance the proliferation of hematopoietic progenitor cells. This process leads to an increased number of osteoclasts and other hematopoietic cells, and to enhanced resorption of bone tissue and extension of hematopoietic territories. ${ }^{28)}$ Therefore, the inclusion of women with anemia in future studies would allow us to more clearly delineate the association between hemoglobin level and BMD.

In addition to the previous comment regarding our selection criteria, this study had some limitations. First, the study population was comprised of participants aged 20-49 years who had visited a health promotion center and were retrospectively selected according to specific criteria. These factors may have introduced selection bias. Second, causality could not be clearly determined because of the crosssectional nature of the study. A prospective cohort study would therefore be needed to confirm our findings. Third, we did not measure serum ferritin level, a useful marker of iron storage, in contrast to many previous studies on the association between iron levels and BMD. However, serum ferritin is also considered an acute-phase reactant and may be artificially elevated in response to systemic inflammation. ${ }^{23)}$ Accordingly, this marker may not accurately reflect the severity 
of iron overload. Therefore, we chose to use serum iron level rather than serum ferritin level. Fourth, we could not control for individual vitamin D levels, which could affect BMD. Fifth, we did not exclude other factors that could have affected BMD. Finally, we could not exclude women who had their menstrual period at the time of examination, which could have affected their BMDs, hemoglobin levels, and iron levels. However, the strengths of this study include the large sample size and relatively rare use of serum iron level, rather than ferritin level, to confirm iron overload. Another strength of this study was the minimizing effects of menopause, which were factors that significantly affected BMD. Therefore, we believe that these data are valuable and should be considered during the clinical treatment of patients with a reduced BMD.

In conclusion, we observed negative and positive associations between changes in BMD of the lumbar spine and elevated serum iron level and TIBC in in a population of healthy premenopausal Korean women. Our study differed from previous research in that we used serum iron level, TIBC, and hemoglobin level, rather than serum ferritin level, to determine the relationship between iron storage and BMD. This novel method has provided a new perspective from which to evaluate the relationship between iron storage and BMD. We believe that our study findings will contribute to the treatment and care of young women, and may provide a foundation for subsequent studies such as the large-cohort and multicenter studies, which are needed to confirm the causal relationship between iron storage and BMD.

\section{CONFLICT OF INTEREST}

No potential conflict of interest relevant to this article was reported.

\section{ORCID}

Sung-Min Kim: https://orcid.org/0000-0001-9942-6893

A-Sol Kim: https://orcid.org/0000-0003-2497-9500

Hae-Jin Ko: https://orcid.org/0000-0003-4460-1476

Hana Moon: https://orcid.org/0000-0003-4604-3746

Hye-In Choi: https://orcid.org/0000-0001-9438-8680

Jieun Song: https://orcid.org/0000-0002-0529-1084

\section{REFERENCES}

1. Willson T, Nelson SD, Newbold J, Nelson RE, LaFleur J. The clinical epidemiology of male osteoporosis: a review of the recent literature. Clin Epidemiol 2015;7:65-76.

2. World Health Organization. Assessment of fracture risk and its application to screening for postmenopausal osteoporosis. Geneva: World Health Organization; 1994.

3. National Health Insurance Service. Silence thief: osteoporosis [Internet]. Wonju: National Health Insurance Service; 2017 [cited 2018 Nov 6]. Available from: https://www.nhis.or.kr/bbs7/boards/B0039/24966.

4. Mutlu M, Argun M, Kilic E, Saraymen R, Yazar S. Magnesium, zinc and copper status in osteoporotic, osteopenic and normal post-meno- pausal women. J Int Med Res 2007;35:692-5.

5. Chee WS, Suriah AR, Zaitun Y, Chan SP, Yap SL, Chan YM. Dietary calcium intake in postmenopausal Malaysian women: comparison between the food frequency questionnaire and three-day food records. Asia Pac J Clin Nutr 2002;11:142-6.

6. Sushma D, Dinesh K. Metal Bhasmas: a possible source of trace elements. Int J Ayurveda Pharma Res 2016;4:72-4.

7. Gur A, Colpan L, Nas K, Cevik R, Saraç J, Erdogan F, et al. The role of trace minerals in the pathogenesis of postmenopausal osteoporosis and a new effect of calcitonin. J Bone Miner Metab 2002;20:39-43.

8. Hunt JR. Bioavailability of iron, zinc, and other trace minerals from vegetarian diets. Am J Clin Nutr 2003;78(3 Suppl):633S-9S.

9. Patel M, Ramavataram DV. Non transferrin bound iron: nature, manifestations and analytical approaches for estimation. Indian J Clin Biochem 2012;27:322-32.

10. Toxqui L, Vaquero MP. Chronic iron deficiency as an emerging risk factor for osteoporosis: a hypothesis. Nutrients 2015;7:2324-44.

11. Chon SJ, Choi YR, Roh YH, Yun BH, Cho S, Choi YS, et al. Association between levels of serum ferritin and bone mineral density in Korean premenopausal and postmenopausal women: KNHANES 2008-2010. PLoS One 2014;9:e114972.

12. Lee KS, Jang JS, Lee DR, Kim YH, Nam GE, Han BD, et al. Serum ferritin levels are positively associated with bone mineral density in elderly Korean men: the 2008-2010 Korea National Health and Nutrition Examination Surveys. J Bone Miner Metab 2014;32:683-90.

13. Doyard M, Chappard D, Leroyer P, Roth MP, Loreal O, Guggenbuhl P. Decreased bone formation explains osteoporosis in a genetic mouse model of hemochromatosiss. PLoS One 2016;11:e0148292.

14. Olynyk JK, Trinder D, Ramm GA, Britton RS, Bacon BR. Hereditary hemochromatosis in the post-HFE era. Hepatology 2008;48:991-1001.

15. Wang L, Yu H, Yang G, Zhang Y, Wang W, Su T, et al. Correlation between bone mineral density and serum trace element contents of elderly males in Beijing urban area. Int J Clin Exp Med 2015;8:19250-7.

16. Liu SZ, Yan H, Xu P, Li JP, Zhuang GH, Zhu BF, et al. Correlation analysis between bone mineral density and serum element contents of postmenopausal women in Xi'an urban area. Biol Trace Elem Res 2009;131:205-14.

17. Gunzerath L, Faden V, Zakhari S, Warren K. National Institute on Alcohol Abuse and Alcoholism report on moderate drinking. Alcohol Clin Exp Res 2004;28:829-47.

18. Walmsley TA, George PM, Fowler RT. Colorimetric measurement of iron in plasma samples anticoagulated with EDTA. J Clin Pathol 1992;45:151-4.

19. Cohen A, Shane E. Treatment of premenopausal women with low bone mineral density. Curr Osteoporos Rep 2008;6:39-46.

20. Tsay J, Yang Z, Ross FP, Cunningham-Rundles S, Lin H, Coleman R, et al. Bone loss caused by iron overload in a murine model: importance of oxidative stress. Blood 2010;116:2582-9.

21. Chaudhri MA, Kemmler W, Watling J. Trace elements in osteopenia/ osteoporosis: a potential, quick, simple and cheap method for BMD assessment. In: Kim SI, Suh TS, editors. World Congress on Medical Physics and Biomedical Engineering 2006. Berlin: Springer; 2007. p. 906-8.

22. Barton JC, Edwards CQ, Phatak PD, Britton RS, Bacon BR. Handbook of iron overload disorders. Cambridge: Cambridge University Press; 
2010.

23. Kim BJ, Ahn SH, Bae SJ, Kim EH, Lee SH, Kim HK, et al. Iron overload accelerates bone loss in healthy postmenopausal women and middleaged men: a 3-year retrospective longitudinal study. J Bone Miner Res 2012;27:2279-90.

24. Ballas SK. Normal serum iron and elevated total iron-binding capacity in iron-deficiency states. Am J Clin Pathol 1979;71:401-3.

25. Braunstein EM. Iron deficiency anemia. Kenilworth (NJ): Merck Sharp \& Dohme Corp.; 2016.
26. Cesari M, Pahor M, Lauretani F, Penninx BW, Bartali B, Russo R, et al. Bone density and hemoglobin levels in older persons: results from the InCHIANTI study. Osteoporos Int 2005;16:691-9.

27. Yoon J, Kim DJ, Sung HH, Jo YK. Analysis of bone mineral density according to hemoglobin in university students. Korean J Clin Lab Sci 2016;48:296-303.

28. Gurevitch O, Slavin S. The hematological etiology of osteoporosis. Med Hypotheses 2006;67:729-35. 